\title{
Prevalence of Musculoskeletal Disorders among Indian Dentists: A Pilot Survey with Assessment by Rapid Entire Body Assessment
}

\author{
${ }^{1}$ Sumita Bhagwat, ${ }^{2}$ Sameeksha Hegde, ${ }^{3}$ Lalitagauri Mandke
}

\begin{abstract}
Introduction: Musculoskeletal disorders (MSDs) are increasingly becoming a nuisance for dental professionals. Nearly, 2 million workers across the world suffer from MSDs each year, with dentists facing an increased risk of developing these ailments.

This study is an attempt to assess the risk of MSDs among dental professionals, and eventually to spread awareness regarding the importance of good posture and proper ergonomics.
\end{abstract}

Objectives: To determine the presence of MSDs among Indian dentists.

Materials and methods: A research survey was conducted among dental professionals practicing in and around Maharashtra state, India. The questionnaire for the study included a series of questions, when coupled with the rapid entire body assessment (REBA) scale, allows one to assess his/her posture during work and eventually determines the need to improve the same. Two hundred dentists completed the questionnaire given.

Result: The study revealed a high prevalence of musculoskeletal pain among dental professionals.

Conclusion: A relation was observed between the severity of the pain experienced by the dentists and their REBA score indicating that dentists with a higher REBA score need to adapt their working postures and employ proper ergonomics.

Keywords: Backache, Dental professionals, Indian dentists, Musculoskeletal disorders, REBA.

How to cite this article: Bhagwat S, Hegde S, Mandke L. Prevalence of Musculoskeletal Disorders among Indian Dentists: A Pilot Survey with Assessment by Rapid Entire Body Assessment. World J Dent 2015;6(1):39-44.

\section{Source of support: Nil}

Conflict of interest: None

\footnotetext{
${ }^{1}$ Professor and Postgraduate Guider, ${ }^{2}$ Senior Resident ${ }^{3}$ Professor and Head

${ }^{1-3}$ Department of Conservative Dentistry and Endodontics Padmashree Dr DY Patil Dental College and Hospital, Navi Mumbai, Maharashtra, India
}

Corresponding Author: Sumita Bhagwat, Professor and Postgraduate Guider, Department of Conservative Dentistry and Endodontics, Padmashree Dr DY Patil Dental College and Hospital Nerul, Navi Mumbai, Maharashtra, India, Phone: 022-21713763 9819876828, e-mail: sumita1572@gmail.com

\section{INTRODUCTION}

Numerous events have transformed the practice of dentistry into one that is more efficient, comfortable for the patient and more productive for the dentist. Until reasonably recently, dentistry was exclusively practiced in a standing posture. 1960s changed the face of dentistry to four-handed practice, and sitting became the preferred way of rendering treatment. ${ }^{1,2}$ In 1954, a group of dentists, including Dr Sanford S Golden, met to develop a reclining chair for the patient that would allow the dentist to sit while operating. ${ }^{3}$ The introduction of the Dental-Ez chair, by John Naughton 1958, was the event that ushered in the era of modern sit down, four-handed dentistry. ${ }^{3}$ Though modern dentistry has evolved substantially today, dental professionals are commonly exposed to a variety of occupational hazards. The back has long been affected by the postures adapted by the dentists, causing musculoskeletal disorders (MSDs). Because of MSDs, dentists have often had to limit or even abandon their professional practice. ${ }^{4}$

Different researchers with different methodologies investigated musculoskeletal disorders among dentists. Musculoskeletal disorders have been associated with several risk factors, like prolonged static posture, repeated performance of same actions, poor illumination, incorrect position of the patient on the dental chair, genetic predisposition, work pressures, stress, lack of exercise and age. The overall prevalence of MSDs in dentistry differs from 63 to $93 \%$ worldwide. ${ }^{4}$

The aim of this pilot survey was to assess the prevalence of MSDs among dentist in India by surveying a representative sample size.

\section{MATERIALS AND METHODS}

A cross-sectional questionnaire-based contact survey was carried out among 200 dentists in and around Maharashtra, as a representative pool for dentists in India. The representative pool consisted of private and public practitioners, with general good health.

\section{Questionnaire and Data Collection}

The questionnaire was divided into different sections so as to understand and assess the different variables 
involved. The questionnaire recorded the basic demographic features, the working conditions of the dental professionals and responses, specifically pertaining to the existing MSDs. The rapid entire body assessment (REBA) tool was employed for assessment within the questionnaire. ${ }^{5}$ Rapid entire body assessment is a postural targeting method for estimating the risks of workrelated entire body disorders. Rapid entire body assessment gives a rapid, reliable and detailed assessment of the complete body postural risks to any individual who is involved in distinct and repetitive physical work pattern. Musculoskeletal disorders were recorded as aches, pain and discomfort in any region of the body.

\section{STATISTICAL ANALYSIS}

Being an exploratory study, mostly the data were presented in counts and percentages. Chi-square test was used to evaluate the correlation between the occurrence of pain and factors affecting it. Statistical package for social sciences (SPSS) software 16.0 was used to perform the statistical analysis.

\section{RESULTS}

This study examined the presence and distribution of self-reported MSD and assessed the potential risks of MSD among a cross-section of dentists in and around Maharashtra.

\section{Prevalence of Musculoskeletal Pain}

Two hundred dental professionals answered the questionnaire, 89 males and 111 females. The mean of ages \pm SD was $35 \pm 5$ within a range from 25 to 45 years. Seventy-two of the participants were general dentists and 128 were specialists. Their major tasks were operative dentistry followed by endodontic, prosthodontics, oral surgery, and periodontics. One hundred and fifteen respondents $(57.5 \%)$ had complains of musculoskeletal pain, while 85 (42.5\%) had no complaint (Graph 1). One hundred and twenty-one respondents $(60.50 \%)$ did not perform any exercise in the day and $79(39.50 \%)$ performed regular exercise. Four-handed dentistry was practiced by $49.50 \%$ of professionals.

Fifty-nine percent respondents preferred sitting and working, $13.5 \%$ respondents preferred standing position and $27.5 \%$ alternated between standing and sitting posture during work. Sixty-six percent (133) of the dentists did take breaks between appointments.

\section{Prevalence of Painful Sites}

The questionnaire revealed that the common painful sites for different body parts were different for males and females (Table 1).

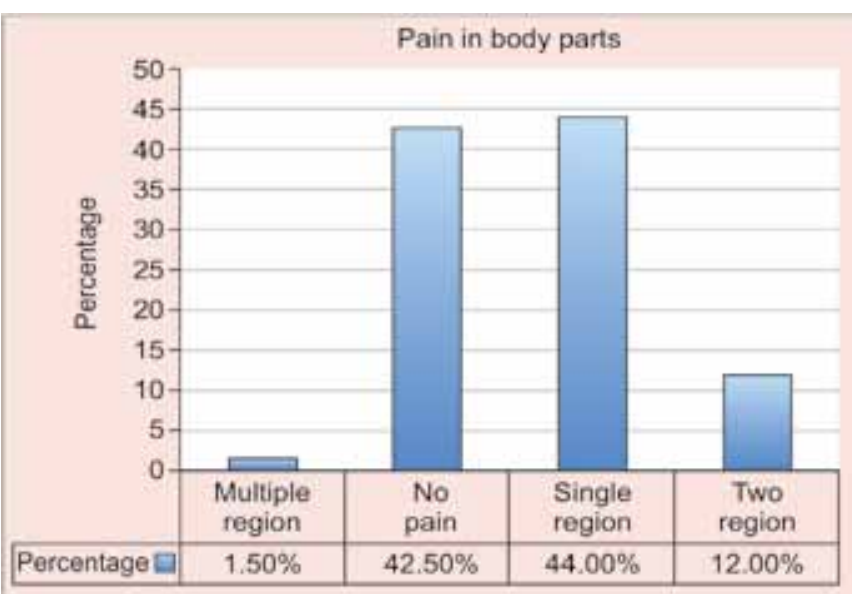

Graph 1: Pain in body parts according to participant responses

Table 1: Common painful sites for different body parts

\begin{tabular}{lll}
\hline Pain sites & Males (\%) & Females (\%) \\
\hline Back & 34.83 & 41.57 \\
Neck & 23.60 & 34.83 \\
Shoulders & 3.37 & 10.11 \\
Elbow & 3.37 & 0.00 \\
Heel & 2.25 & 0.00 \\
Knee & 0.00 & 1.12 \\
Feet & 0.00 & 2.25 \\
Leg & 0.00 & 1.12 \\
\hline
\end{tabular}

Table 2: According to the REBA questionnaire, contributors were divided into three main risk groups due to their action levels

\begin{tabular}{lll}
\hline Risk & Score & Percentage \\
\hline Low risk & $2-3$ & $10 \%(20)$ \\
Medium risk & $4-7$ & $84 \%(168)$ \\
High risk & $8-10$ & $6 \%(12)$ \\
\hline
\end{tabular}

The most common positions acquired by the practitioners for different sites as per REBA ${ }^{5}$ are depicted in Figures 1 to 7 .

According to the REBA questionnaire, contributors were divided into three main risk groups due to their action levels (Table 2 and Graph 2).

\section{DISCUSSION}

Dentistry is a high-risk profession for MSDs. Most dental professionals constantly complain of pain in some region in their professional life span.

Dental professionals need to visualize the exact field of work and this adds a lot of strain on their muscles, as they need to be in the same position for a prolonged duration of time. Several repetitive small ranges of motions are involved in dental practice.

Four-handed dentistry was suggested and equipment was developed within the ergonomic promotion mainly because of complaints of MSDs in dentists. Although it could not cease the pain, related literature drops a hint that the painful sites have altered. ${ }^{4}$ 


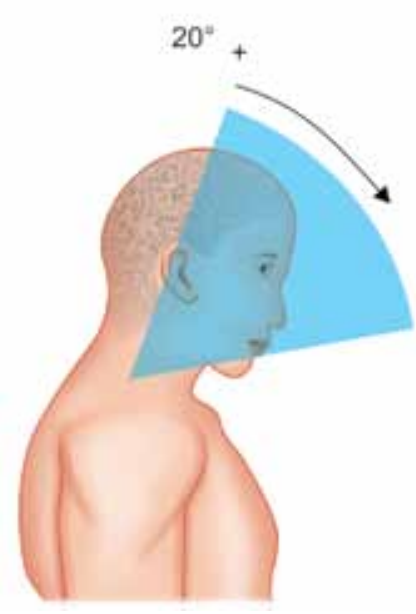

Fig. 1: Most commonly adopted neck position: $74.5 \%$ (149)

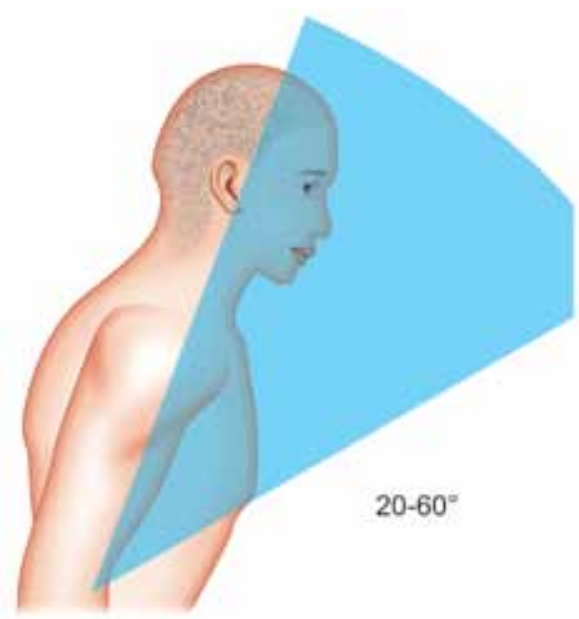

Fig. 2: Most commonly adopted trunk position: $41 \%(82)$

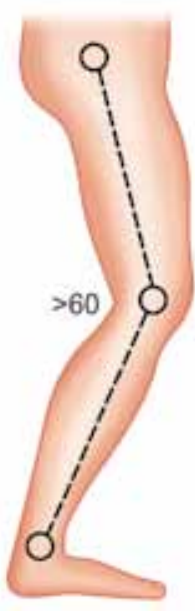

Fig. 3: Most commonly adopted leg position-sitting: $60 \%(45)$

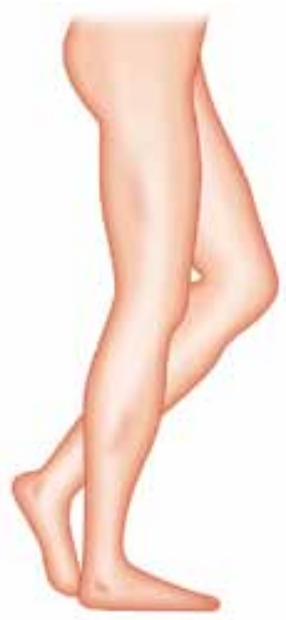

Fig. 4: Most commonly adopted leg positionstanding: $59 \%(98)$

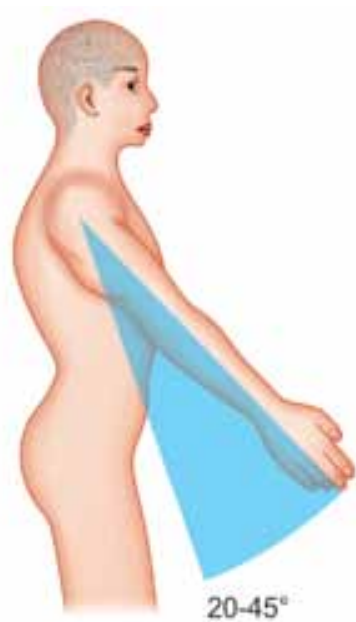

Fig. 5: Most commonly adopted upper arm position: $57 \%$ (114)

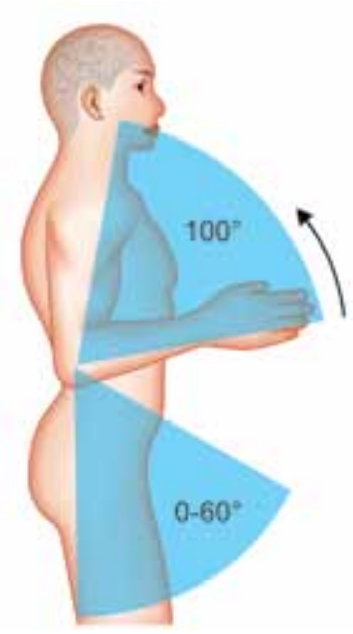

Fig. 6: Most commonly adopted lower arm position: $56 \%$ (112)

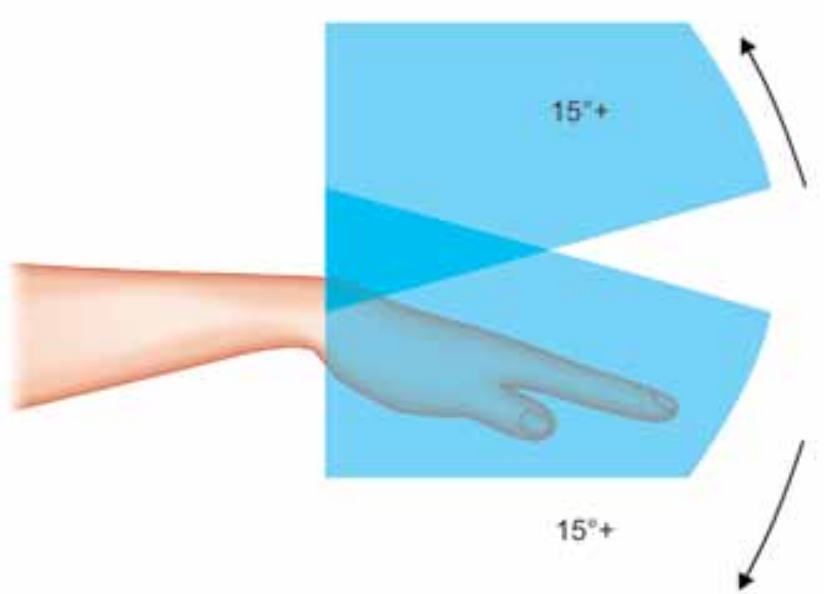

Fig. 7: Most commonly adopted wrist position: $57.50 \%$ (115)

Our study included dental practitioners around age group of $35 \pm 5$ years. Among the different age groups, we found that the presence of painful sites were maximum in the above 40 years group, $70.8 \%$, also seen in Graph 3, factors affecting MSDs among a cross-section of dentists practicing in private and hospices. The sample was a representative sample for a pilot study. 


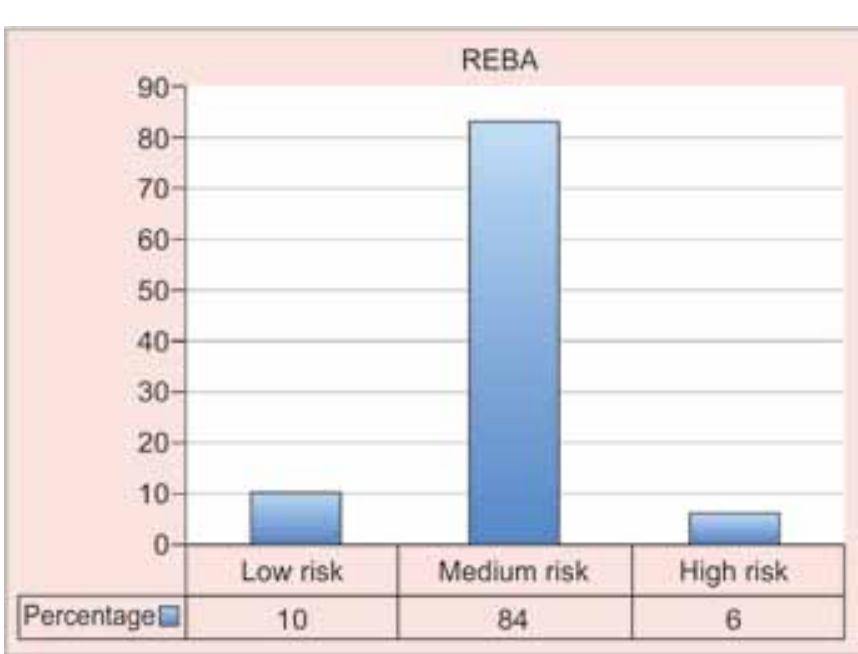

Graph 2: Division of contributors into three main risk groups according to their REBA scores

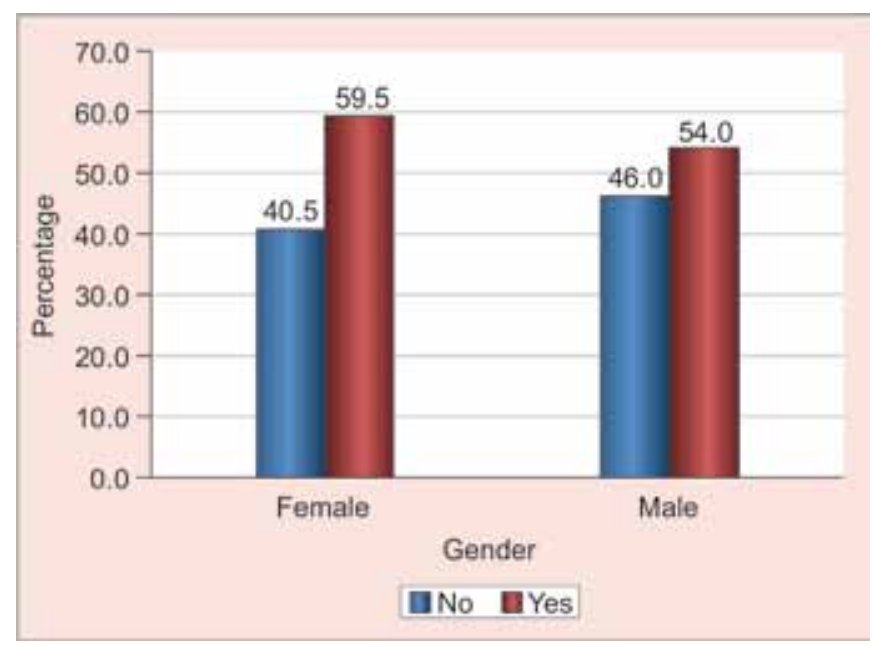

Graph 4: Correlation between presence of pain and gender in participants [using Chi-square test, $p$-value is 0.068 (> 0.05), i.e. there is no relation between incidence of pain and gender]

and there was a significant relationship between age and pain incidence. The investigation revealed that more than half the sample size suffered from some painful sites of which females (59.5\%) suffered more compared to men (54.5\%), depicted in Graph 4 . We found the back and the neck were the most painful regions but males and females had different regions of pain (Table 1). More than half of the dental professionals did not perform any exercise or indulge in any sport on daily basis and this increased their risk of having musculoskeletal disorders. Although a lot of professionals, 71\% (133) took breaks in between appointments; nevertheless $56 \%$ still suffered pain from musculoskeletal disorders. Even after the evolution to seated four-handed dentistry and ergonomic equipment, studies found that back, neck, shoulder or arm pain was present in up to $81 \%$ of dental operators. ${ }^{6}$ In our survey, we found that $66 \%$ (133) of the dentist did take breaks in between appointments, however, $55.6 \%$ of them still had

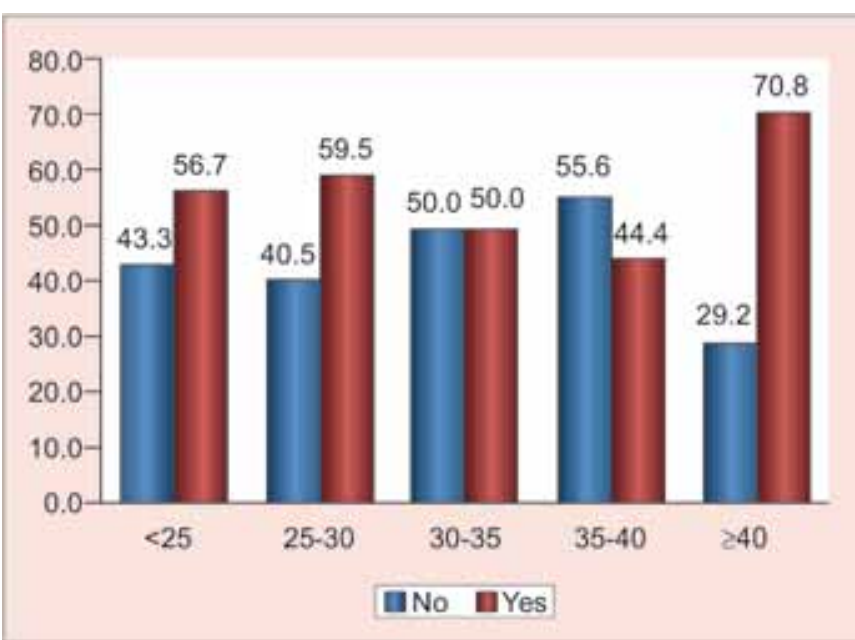

Graph 3: Age group wise presence of pain in participants [using Chi-square test, $p$-value is $0.029(<0.05)$, i.e. there is a relation between incidence of pain and age group]

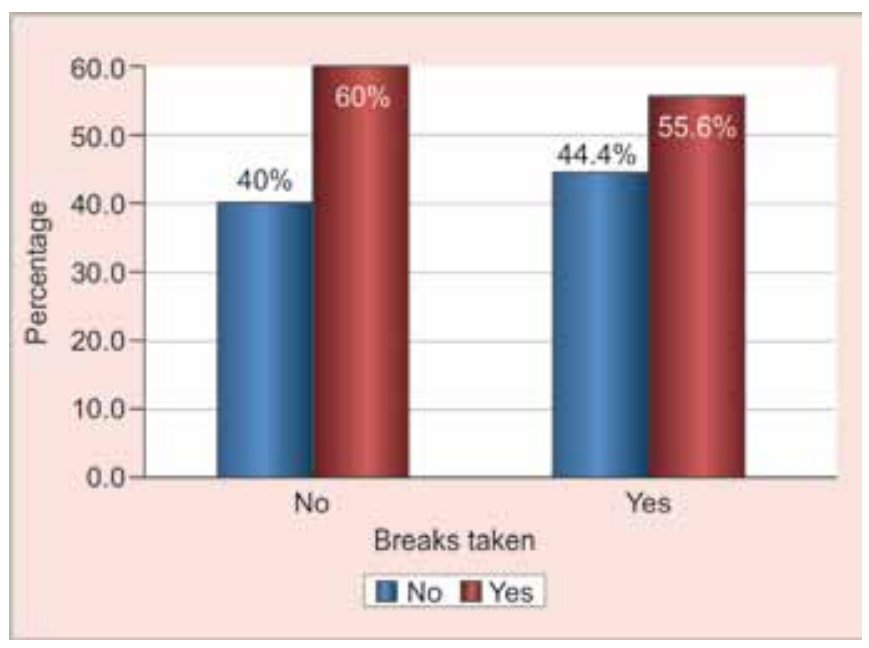

Graph 5: Correlation between presence of pain and breaks taken by participants [using Chi-square test, $p$-value is $0.043(<0.05)$, i.e. there is a relation between incidence of pain and breaks taken]

pain which signifies that they did not relax their strained muscles during this time (Graph 5). Though four-handed dentistry was being practised by $49.50 \%$ dentists, $56.7 \%$ of those still suffered from pain while $57.6 \%$ of practitioners without assistance also suffered from pain. Chi-square test revealed a correlation between the two (Graph 6).

We compared our findings with those of other investigators in similar studies ${ }^{7-19}$ all around the world with site specific pain results (back, neck and shoulders). It was found that work-related MSDs among dental professions were present worldwide (Tables3 to 5), and our findings were relatively in agreement with the findings of most researchers.

Many researchers have determined that the mechanisms leading to work-related musculoskeletal pain are multifactorial. ${ }^{20,21}$ This pain can be related with several risk factors like extended static posture, repeated performance of same actions, poor illumination, incorrect 


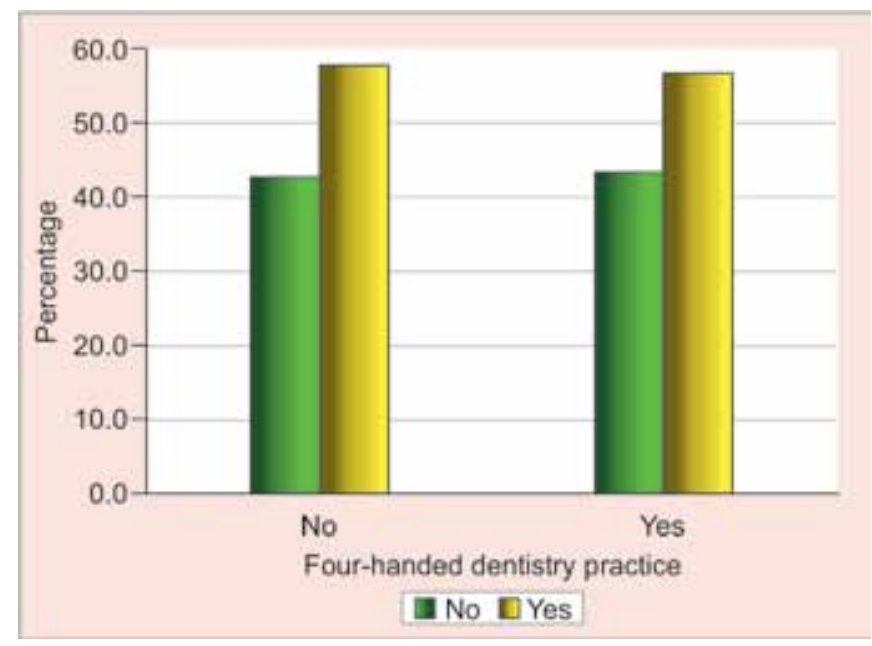

Graph 6: Correlation between incidence of pain and four-handed dentistry practice among participants [using Chi-square test, $p$-value is $0.035(<0.05)$, i.e. there is a relation between incidence of pain and four-handed dentistry practice]

position of the patient on the dental chair, genetic predisposition, work pressures, stress, lack of exercise and age. Dentists are very often in particular still positions, which require more than half the body's muscles to contract and hold the body motionless, while resisting gravity. The still forces resulting from these sustained positions have been shown to be much more troublesome than dynamic forces. ${ }^{22}$ When the human body repeatedly sustains extended periods of static postures, it can cause a series of events that can possiblely lead up to pain and injury or a career-ending MSD, muscle imbalances, ischemia, trigger points, joint hypomobility and spinal disk degeneration. ${ }^{6}$

\section{RECOMMENDATION AND CONCLUSION}

Prevention of chronic pain in dentistry may require a paradigm shift in the basic training and conduct of dental professionals regarding clinical work habits. A multilevel approach is required to treat this multifaceted issue, i.e. practicing four-handed dentistry, proper use of ergonomic dental tools, correct foot-wear, good postural habits, better illumination and magnification, regular stretch breaks and regular exercise are the areas that can be addressed to reduce strain on the musculoskeletal system of the dental professional.

The authors recommend that more conclusive remedial measures be incorporated by addressing the posture-related habits and exercise right from the

Table 3: Incidence of MSDs related to the back

\begin{tabular}{llllllr}
\hline Body site & Sample & MSD (\%) & Country & Year & Author & Reference \\
\hline Back & & 60 & Denmark & 1998 & Finsen et al & 7 \\
& 285 & 54 & Australia & 2006 & Leggat PA and Smith DR & 8 \\
& & Poland & 2002 & Szymanska & 9 \\
& 57 & 45 & Netherlands & 2005 & Droeze and Johnson & 10 \\
& 204 & 36 & Saudi Arabia & 2001 & Alwazzan et al & 11 \\
& 420 & 46 & Greece & 2004 & Alexopoulos EC & 12 \\
& 220 & 35 & Poland & 2011 & Kierklo A & 13 \\
227 & 13.2 & Brazil & 2009 & De Carvalho MV et al & 14 \\
& 30 & 73.3 & India (Mangalore) & 2011 & Shaikh AR & 15 \\
& 114 & 32.5 & Italy & 2004 & Marcello M & 16 \\
& 568 & 64 & Malaysia & 2013 & Khan SA et al & 17 \\
& 34 & India (Mumbai) & $2013-14$ & Our study & \\
\hline
\end{tabular}

Table 4: Incidence of MSDs related to the neck

\begin{tabular}{llllllr}
\hline Body site & Sample & MSD (\%) & Country & Year & Author & Reference \\
\hline Neck & & 60 & Denmark & 1998 & Finsen et al & 7 \\
& 285 & 57 & Australia & 2006 & Leggat PA and Smith DR & 8 \\
& 110 & 85 & Sweden & 1999 & Akesson et al & 18 \\
& 56 & Poland & 2002 & Szymanska & 9 \\
& 57 & Netherlands & 2005 & Droeze and Johnson & 10 & 11 \\
& 204 & 20 & Saudi Arabia & 2001 & Alwazzan et al & 12 \\
& 420 & 26 & Greece & 2004 & Alexopoulos EC & 13 \\
& 220 & 47 & Poland & 2011 & Kierklo A & 14 \\
& 227 & 4 & Brazil & 2009 & De Carvalho MV et al & 15 \\
& 30 & 23.3 & India (Mangalore) & 2011 & Shaikh AR & 16 \\
& 114 & 40.4 & Italy & 2004 & Marcello M & 17 \\
& 568 & 82 & Malaysia & 2013 & Khan SA et al & Our study \\
\hline
\end{tabular}


Table 5: Incidence of MSDs related to the shoulders

\begin{tabular}{llllllr}
\hline Body site & Sample & MSD (\%) & Country & Year & Author & Reference \\
\hline Shoulder & 5000 & 21 & United States & 2001 & Lalumandier et al & 19 \\
& 57 & 52 & Netherlands & 2005 & Droeze and Johnson & 10 \\
& 285 & 53 & Australia & 2006 & Leggat PA and Smith DR & 8 \\
& 227 & 2 & Brazil & 2009 & De Carvalho MV et al & 14 \\
& 420 & 20 & Greece & 2004 & Alexopoulos EC & 12 \\
& 220 & 20 & Poland & 2011 & Kierklo A & 13 \\
& 30 & 40 & India (Mangalore) & 2011 & Shaikh AR & 15 \\
& 568 & 26 & Malaysia & 2013 & Khan SA et al & 17 \\
\hline
\end{tabular}

undergraduate training of a dental student so that incidence of work-related MSDs can be greatly reduced in the future.

\section{REFERENCES}

1. Martin MM, Ahearn D, Gotcher J, et al. An introduction to ergonomics: risk factors, MSDs, approaches and interventions-a report of the Ergonomics and Disability Support Advisory Committee (EDSAC) to Council on Dental Practice (CDP). Chicago, IL: American Dental Association 2004

2. Inside dental assisting 2012 Sept/Oct;10(5).

3. Schulein TM. Significant events in the history of operative dentistry. J Hist Dent 2005 Jul;53(2):63-72.

4. Rabiei M, Shakiba M, Shahreza HD, Talebzadeh M. Musculoskeletal disorders in dentists. Int J Occupational Hygiene 2012 Jan;4(1):36-40.

5. Hignett S, McAtamney L. Rapid entire body assessment. Appl Ergon 2000 Apr;31(2):201-205.

6. Valachi B, Valachi K. Mechanisms leading to musculoskeletal disorders in dentistry. J Am Dent Assoc 2003 Oct;134(10):1344-1350.

7. Finsen L, Christensen H, Bakke M. Musculoskeletal disorders among dentists and variation in dental work. Appl Ergon 1998 Apr;29(2):119-125.

8. Leggat PA, Smith DR. Musculoskeletal disorders selfreported by dentists in Queensland, Australia. Aust Dent J 2006 Dec;51(4):324-327.

9. Szymańska J. Disorders of the musculoskeletal system among dentists from the aspect of ergonomics and prophylaxis. Ann Agric Environ Med 2002;9(2):169-173.

10. Droeze EH, Johnson H. Evaluation of ergonomic interventions to reduce musculoskeletal disorders of dentists in the Netherlands. Work 2005;25(3):211-220.

11. AlWazzan KA, Almas K, ElShethri SE, AlQuahtani MQ. Back and neck problems among dentists and dental auxiliaries. J Contemp Dent Pract 2001;2:1-10.
12. Alexopoulos EC, Stathi IC, Charizani F. Prevalence of musculoskeletal disorders in dentists. BMC Musculoskelet Disord 2004;5:16.

13. Kierklo A, Kobus A, Jaworska M, Botuliński B. Work-related musculoskeletal disorders among dentists-a questionnaire survey. Ann Agric Environ Med 2011 Jun;18(1):79-84.

14. De Carvalho MV, Soriano EP, de França Caldas A Jr, Campello RI, de Miranda HF, Cavalcanti FI. Work-related musculoskeletal disorders among brazilian dental students. J Dent Educ 2009 May;73(5):624-630.

15. Shaikh AR, Rao SB, Husain A, D'sa J. Work related musculoskeletal disorders among dental surgeons: a pilot study. Contemp Clin Dent 2011 Oct;2(4):308-312.

16. Marcello M, Abou-Atme YS, Cottogno L, Pittau R. Upper body musculoskeletal symptoms in Sardinian dental students. J Can Dent Assoc 2004 May;70(5):306-310.

17. Khan SA, Chew KY. Effect of working characteristics and taught ergonomics on the prevalence of musculoskeletal disorders amongst dental students. BMC Musculoskelet Disord 2013 Apr 2;14:118.

18. Akesson I, Johnsson B, Rylander L, Moritz U, Skerfving S. Musculoskeletal disorders among female dental personnel -clinical examination and a 5-year follow-up study of symptoms. Int Arch Occup Environ Health 1999;72:395-403.

19. Lalumandier JA, McPhee SD, Parrott CB, Vendemia M. Musculo-skeletal pain: prevalence, prevention, and differences among dental office personnel. Gen Dent 2001;49(2):160-166.

20. Rundcrantz BL, Johnsson B, Moritz U, Roxendal G. Occupational cervico-brachial disorders among dentists. Psychosocial work environment, personal harmony and life-satisfaction. Scand J Soc Med 1991 Sep;19(3):174-180.

21. Westgaard RH. Effects of physical and mental stressors on muscle pain. Scand J Work Environ Health 1999;25(Suppl 4):19-24.

22. Ratzon NZ, Yaros T, Mizlik A, Kanner T. Musculoskeletal symptoms among dentists in relation to work posture. Work 2000;15(3):153-158. 